\title{
Collaboration in Arts Education
}

Jeff Adams

The merits of collaborative learning through the arts are immediately obvious: many of the arts physically lend themselves to shared contributions and joint productions theatre, dance, murals, singing, textiles, graphics, design and printing, to name only the first to spring to mind. Underpinning each of these are social and communal learning: how to be together, and share in an enterprise. This is turn feeds into the idea of a democratic society where the learner is not only acquiring knowledge and skills, but also an understanding of what it is to be a citizen; it is hard to overestimate how important being well socialised at an early age is to the coherence of a functioning civic society.

Given the seemingly obvious advantages of such an education, and the equitable society that it is designed to support, it is troubling that collaborative education, and with it arts education, is increasingly neglected in favour of individual and competitive learning. In the West a much reduced and peculiarly specific idea of education persists, with individual learning and achievement as its fundamental model. Stemming from 19th-century Romanticism, it applies as much to creativity and the arts as it does to the sciences. This conception has surprising longevity, given the huge social changes that have occurred since the Romantic period, but persist it does, and it permeates our consciousness of what it means to be artistic as well as to be educated.

Nowhere is this more apparent than in school assessment regimes, which have been yoked permanently to this competitive model with the advent of PISA ('Programme for International Student Assessment' - note the singular form of 'student'). This has become the dominant means of calibrating and comparing education systems across the world by competitive performance, whereby these ideals are ossified and fortified, and given far greater authority than they merit. It doesn't take much research and analysis, or even experience of working in education at almost any level, to realise that many things are more successfully achieved through group and collaborative work, and it's not difficult to find evidence that communal and collective learning opportunities are obstructed or even eradicated by the insistence on individualised assessment. Add to this the neoliberal notion that achieving personal advantage is more valuable than contributing to the good of society, and you have a rather toxic zeitgeist prevailing. 
Collaboration has its own problems, of course, and the global corporatisation of education, which jagodzinski discusses in this issue, are a clear reminder of this. Collaboration in the arts can also be hard to plan and manage, since social interaction frequently leads to unexpected outcomes, not always positive ones, and requires dynamic and diverse pedagogical methods on the part of the educator. These may also be called into question more readily by a collaborative response from the learners, which may lead to uncomfortable situations where rationales are interrogated and criticised during a session; all the more so if the teacher is not responsible for devising the content of the work to be 'delivered', as is the trend in Western education where teachers are increasingly expected to take responsibility for their learners' performance, even where they have little power over the curriculum or pedagogy. Seen in this way collaborative, communal and social learning become a litmus test of teacher autonomy and agency: the less power and control over the curriculum, the less likely they are to engage in collaborative activity.

In arts education the consequence of this is that collaboration is shunned whenever a formal learning situation leads to an assessment - and increasingly all learning situations are expected to be calibrated in some way. The problem is not to do with individualised learning or assessment per se; a curriculum that comprised entirely of collaborative learning approaches would be equally detrimental; it's a problem of balance and diversity: just as the inequality between the status of the arts and the sciences skews the balance of a curriculum, so the faith in a totalising system of competitive and individualised learning produces a reduced and distorted shadow of what education might be. How then might we salvage the collaborative, the communal and the social in the arts, in all its rich and diverse forms, from the ravages of this historic obsession with individualism? This problem, and its many variants, formed the basis of this conference.

Such were the questions and dilemmas that sparked the fifth iJADE international conference that took place at Tate Liverpool and Liverpool Maritime Museum over two days in November 2014. Organised by RECAP (Research into Education, Creativity and Arts through Practice) with the support of the National Society for Education in Art and Design (NSEAD), the conference was well attended by delegates from the arts education community across the world. In total 17 nationalities were represented, including Hong Kong, South Korea, UAE, China, 
Australia, Taiwan, Canada, USA, Chile, Turkey, Serbia, Finland, Cyprus and many European countries, as well as a large number of UK delegates.

The presentations covered a wide range of issues within the theme of collaboration in the field of arts education. Some of the foremost thinkers on arts education were keynote presenters: jan jagodzinski gave an address on the appropriation of collaborative practices by designer capitalism, which is reproduced in this issue. Kerry Thomas gave a keynote, also reproduced in this issue, which spoke of the different types and levels of collaboration and of the ethical complexities of introducing them into the curriculum. Janna Graham, curator and educator at the Serpentine Gallery in London, discussed collaborative arts responses of local neighbourhoods in London that are subject to disadvantageous development.

More than 60 sessions were organised around nine subthemes: disciplines and institutions; co-creation within gallery education; pedagogical methodologies; approaches to design; early years and primary education; practice-led research; learning communities; teacher education, and democratic education. NSEAD president Susan Coles closed the conference with an upbeat talk about collaborative professional development for art teachers.

One of the purposes of the iJADE conference is to generate and support new writing and new research in arts education. Each year the conference encourages this by featuring a delegate nomination system for outstanding presentations, where the nominated authors are invited to submit a version of their paper for publication in a conference issue such as this. Each article contained in this issue was invited by the editorial team following the conference and guided by the delegates' nominations, and is an extended version of the paper the author(s) presented at the 2014 conference. 